\section{Maximing Learning Strategies To Pomote Learner Autonomy*)}

\author{
Junaidi Mistar \\ Universitas Islam Malang
}

\begin{abstract}
Learning a new language is ultimately to be able to commu nicate with it. Encouraging a sense of responsibility on the part of the learners is crucial for training them to be proficient communicators. As such, understanding the strategies that they employ in acquiring the language skill is important to come to ideas of how to promote learner autonomy. Research recently conducted with three different groups of learners of English at the tertiary education level in Malang indicated that they used metacognitive and social strategies at a high frequency, while memory, cognitive, compensation, and affective strategies were exercised at a medium frequency. This finding implies that the learners have acquired some degrees of autonomy because metacognitive strategies requires them to independently make plans for their learning activities as well as evaluate the progress, and social strategies requires them to independently enhance communicative interactions with other people. Further actions are then to be taken to increase their learning autonomy, that is by intensifying the practice of use of the other four strategy categories, which are not yet applied intensively.
\end{abstract}

Key words: learner autonomy, learning strategies, cognitive psychology, second/foreign language

After enjoying its popularity in the 1950 s to 1960 s, research focus on various approaches to second/foreign language teaching decreased with a shift in research emphasis in the 1970s from the teacher to the learner. Greater independence on the part of the learners has been pursued to replace the traditional teacher-supervised classrooms. The intent to individualise the instruction is also triggered by the fact that a group of learners in a second/foreign language class who receive the same instruction with the same materials from the same teacher gain different levels of success. Thus, such terms as individualised instruction, indepen- dent learning, learner-centred curriculum, self-directed learning, and selfinstruction, all of which carry a nuance of autonomy in learning, are popular among textbook writers, curriculum designers, teachers as well as learners.

The present paper is ultimately aiming at sharing ideas of how to implement English teaching-learning activities so that greater autonomy is built-up on the part of the learners. To gain this goal three points are discussed including the characteristics of autonomous second/foreign language (L2/FL), reasons for promoting autonomy in F2/FL learning, and suggested areas of concerns to promote learner autonomy. The suggestions are derived from research findings of how the learners approach their learning tasks. They are not in the form of practical guidelines of how to carry out the instructional process for developing learner autonomy, but of description of learning strategies that the learners have not yet exercised intensively.

\section{WHO ARE THE AUTONOMOUS F2/FL LEARNERS?}

In order to identify autonomous learners; it is essential that the term autonomous be clearly defined. The word autonomous is the adjective form of autonomy, which is etymologically a legal-political term. It is from the Greek autonomia, itself derived from autonomos, where auto means 'self' and nomos means 'law'. The Australian Oxford Dictionary (Moore, 1999, p. 87) defines it as "the right of self-government; personal freedom; freedom of the will; a self-governing community". Thus, the word autonomy carries a meaning of freedom and independence to govern one's own affairs. In a present general sense it is defined as an ability to manage one's own affairs as opposed to a situation of dependence in which one is subjected to decisions and control from others (Broady \& Kenning, 1996). This definition indicates that autonomous learners are the ones who take charge of their own learning. Holec (1981) mentions that taking charge of one's own learning means to hold the responsibility for all decisions concerning all aspects of learning including:

- determining the objectives

- defining the contents and progressions

- selecting methods and techniques to be used

- monitoring the procedure of acquisition

- evaluating what has been acquired. 
In a similar vein, using the term self-directed learning to refer to autonomy in learning, Knowles $(1975$, p.18) defines it as "a process in which individuals take the initiative, with or without the help of others, in diagnosing learning needs, formulating learning goals, identifying human and material resources for learning, choosing and implementing appropriate learning strategies, and evaluating learning outcomes".

In the context with which we are dealing, the learning of L2/FL, autonomous learners are then those who possess the ability to take charge of their own learning of L2/FL. Wenden (1991) mentions that autonomous F2/FL learners acquire learning strategies, knowledge about learning, and attitudes that enable them to use such skills and knowledge appropriately, efficiently, and independently of a teacher. In another article Wenden (1987) states that one of the goals of the research on F2/FL learning strategies is to promote autonomy in learning. Thus, the acquisition of effective learning strategies is crucial for autonomous learners. As such, it can be argued that good language learners, who have proved to be effective learners, are autonomous learners in the sense that the characteristics of good language learners are also the characteristics of autonomous learners.

Research aiming at figuring out autonomous F2/FL learners was carried out by identifying the strategies that they employ in their endeavour to master the language. A study by Naiman, Frochlich, Stern and Todesco (1978) is perhaps the most well known early investigation on the matter. Using Rubin's identification of characteristics of good language learners (Rubin, 1975), the study resulted in a classification of five strategy types including:

a) an active involvement in learning tasks. Good language learners utilise or even create opportunities for learning as well as practice, search for their own problems in learning and try to cope with them, and utilise their non-learning activities such as watching film and listening to music as learning activities.

b) realisation of language as a system. Good language learners do such things as analysing the L2/FL they learn by making comparisons with their native language, formulating and testing hypotheses about the system.

c) realisation of language as a means of communication and interaction. Good language learners look for or create situations involving communication and they emphasise fluency more than accuracy. d) management of affective demands. Good language learners are not afraid of making mistakes and even they need to laugh at their own mistakes.

e) evaluation of performance in the target language. Good language learners always monitor their performance, seek out any help, even from native speakers, to check if their hypotheses are true and make revisions when they find their hypotheses incorrect.

Stern (1983) classifies the strategies of good language learners in a way that explicates more clearly their autonomy in learning. The classification falls into four categories including:

a. Active Planning Strategy. By this strategy good language learners are active in formulating their own learning goals, participating in learning processes, and monitoring the sequences of the development they have achieved.

b. Academic Learning Strategy. By this strategy good language learners are willing to attend to features of the language, learn and practice them, and monitor their performance.

c. Social Learning Strategy. This strategy includes attempts that good language learners pursue in seeking communicative contacts with target language users and they employ communication strategies to overcome difficulties they encounter.

d. Affective Strategy. Good language learners always try to cope with problems of emotion in their learning tasks such as language shock and stress. They build up positive attitude toward themselves as learners, toward learning tasks, and toward the society and culture of native speakers of F2/FL they are learning.

In short, autonomous F2/FL learners are actively and creatively involved - as a manifestation of their positive attitudes toward themselves as learners and toward language learning activities - in the process of planning, conducting, and evaluating the learning process they encounter.

\section{WHY SHOULD L2/FL LEARNERS BE PROMOTED TO BEAUTONOMOUS?}

The justification for promoting autonomy to L2/FL learners roots in philosophy and cognitive psychology. The philosophical rationale says that human beings have their own right to choose whatever they want to be with regard to their life. Thus, education should be aimed at helping children to mature into autonomous adults. This expectation will not come 
true unless the children are given opportunities to behave autonomously while they are learning. Cotterall (1995) points out that helping learners become more independent in their learning is one way of maximising their life choices.

Cognitive psychology considers learning as information processing, in the sense that learning takes place when learners are able to integrate new information into the schemata of knowledge they already know, which is stored in the long-term memory (Anderson, 1983). As such, the most efficient learners are those who are able to bring their existing knowledge to bear on each new learning task. In other words, efficient learners are those who develop a degree of "psychological autonomy" (Little, 1990, p:8). Anderson (1990) further maintains that the knowledge stored in the long-term memory is of two types: declarative and procedural. Declarative knowledge refers to facts and things that learners know about. It is called declarative because it is the knowledge that the learners are aware of and can declare what it is. Procedural knowledge, on the other hand, refers to knowledge about how to do various cognitive abilities. It is called procedural because it is implicitly reflected in the procedures the learners follow in performing the tasks.

In F2/FL learning context, such an ability to integrate the new knowledge into the old one determines how fast learners will be able to acquire the language skill, which is said to go through three sequential cognitive, associative, and autonomous stages (O'Malley \& Chamot, 1990). In the cognitive stage the learners deliberately try to learn vocabulary items and grammatical structures required for forming correct utterances. This knowledge enables them to describe what words are to be used and in what order they have to be arranged in order to convey a certain massage that they want to communicate to other people. However, this knowledge is not yet enough to facilitate skilled performance; thus, very frequent errors are present.

When the learners have reached the associative stage, their declarative knowledge begins to turn into procedural and this is indicated by less frequent errors they make in both their spoken and written performance. However, their declarative knowledge is not yet completely lost because, while they are starting to be fluent speakers of the language, to a degree they are still aware of the grammatical rules underlying their linguistic production. As a result, some minor mistakes are still prevalent at this stage.
The autonomous level is characterised by the fact that the learners' performance becomes automatic so that they are no longer aware of the grammatical rules they apply in their utterances. In this level, they have been able to produce linguistic performance with ease and with rare minor mistakes. In other words, they have gained adequate expertise in completely performing the language skill they learn.

What is important to note here is that the teachers cannot exercise any control whatsoever over the stages of the language skill acquisition as described above. Rather, the learners' transition from one stage to another occurs only when they are ready, not when the teachers say they should. Thus, teaching activities are just a matter of helping the learners to go through the acquisition stages. Tumber $(1991: 26)$ remarks, "...

learning ... comes about where teachers take on the responsibility of providing for and provoking learning and learners themselves take on responsibility for process and progress". This suggests that success or failure in F2/FL learning will in the end depend more on the autonomy of the learners than on any other factors. Rubin and Thompson (1982:3) jointly state, "you, the language learner, are the most important factor in language learning process. Success or failure will, in the end, be determined by what you yourself contribute".

Krashen's Natural Order Hypothesis (Krashen \& Terrell, 1983) supports the necessity of autonomy in F2/FL, learning. The hypothesis suggests that linguistic units be acquired in a predictable order that is more or less similar across learners. Dulay and Burt (1974), for example, provided empirical evidence by studying if there was a natural sequence of $\mathrm{L} 2$ acquisition common to children of diverse backgrounds learning English. They found that that the sequences of acquisition of eleven grammatical items of English by Spanish and Chinese children were virtually the same. This finding does not mean that the learners acquire a series of linguistic items at the same time, rather that certain linguistic structures seem to be acquired earlier and others are acquired later. Thus, a movement of mastery from one item to the following item depends on how quickly the earlier item is mastered. When learners have mastered a certain item in the order, they are cognitively ready to master the following item. Then, in order that they move quickly from one acquisition stage to the following stage, their effective learning strategies are crucial. 


\section{HOW IS TO BUILD-UP LEARNER AUTONOMY?}

Holec (1980) points out that autonomy is not an inborn capacity, but must be acquired either by informal or formal learning. Dickinson (1987:2) also points out, "autonomy is achieved slowly, through struggling towards it, through careful training and careful preparation on the teacher's part as well as on the learner's, ...". Thus, the classroom teaching-learning process can be designed in such a way that it stimulates autonomy on the part of the learners. As Wenden (1991) states that autonomous learners acquire effective learning strategies, in order to come to ideas of how to promote autonomy of Indonesian learners of English, strategies of how they approach their learning tasks are worth investigating. Then, suggestions of how to promote better learner autonomy can be made by referring to the strategies that they do not use very much.

A research project was recently carried out with Indonesians learning English as a foreign language at tertiary education level (Mistar, in preparation). The ultimate goal of the study is to investigate the structure of relationship between individual differences and learning strategies as well as proficiency attainment. In this occasion, however, only findings that are concerned with learning strategies that the leamers employed in their attempt to master the target language, i.e. English as a foreign language, were addressed. of:

The subjects participating in the project were 386 students consisting

1) students at the English department, Islamic University of Malang representing

those leaming English as a major at a teacher-training department ( $\mathrm{n}$ $=124$ );

2) students at the English department, Gajayana University, Malang, to represent those learning English as a major at a non-teacher training department $(n=126)$;

3) students at the Accounting department, Polytechnic, Brawijaya University, Malang, to represent those learning English as a minor course $(n=136)$

The instrument for collecting the data of the learners' learning strategies was the Strategy Inventory for Language Learning (SILL) as developed by Oxford (1990). It consists of fifty items measuring the frequency of use of the six strategy categories: memory, cognitive, compensation, metacognitive, affective, and social strategies. The memory strategies are assessed in nine items measuring the extent to which learners employ various strategies to remember more effectively such as grouping, using imagery and sounds, and reviewing in a structured way. Cognitive strategies are assessed in fourteen items measuring to what extent learners use mental processing strategies such as repeating, practising with sounds and writing systems, and skimming as well as scanning. Compensation strategies are assessed in six items measuring the extent to which learners compensate for missing information by using such strategies as trying to understand the overall meaning, and findings ways to communicate in speaking or writing despite limited knowledge of the language. Metacognitive strategies are assessed in nine items measuring to what extent learners organise and evaluate their learning. Included in this category are setting objectives, learning from errors, and evaluating progresses. Affective strategies are assessed in six items measuring the extent to which learners manage their emotions in learning such as lowering anxiety, taking risks, and talking to someone about feelings and attitudes. Social strategies are also assessed in six items measuring how frequently students learn the language with others such as their peers and proficient users of the target language.

The items of the instrument are constructed in the form of statements, to each of which the subjects are required to provide a response as to what extent the statement is true of them. The response ranges from 1 to 5 , where 1 indicates that the statement is never or almost never true of them and 5 indicates that it is always or almost always true of them. An analysis on the reliability coefficient found an alpha value of .92 for the whole measure. This suggests that in general the items in the inventory measure similar characteristics (Gronlund \& Linn, 1990) indicating that the instrument is reliable for the present subjects. The calculation of the coefficient of each measure of strategy categories found alpha values of $.74, .80, .66, .85, .61$, and .72 for memory, cognitive, compensation, metacognitive, social, and affective strategies respectively. Lower coefficients, but still within an acceptable range, were obtained due to a decrease in the number of items computed for each section.

The interpretation of the findings is made based on the average score of the use of the strategies using the following criteria:

- low use if the average is between 1.00 to 2.44 ; 
- medium use if the average is between 2.45 to 3.44 ; and

- high use if the average is between 3.45 to 5.00 .

The analysis found that the least frequently used strategy category was compensation strategies with an average score of $3.07(\mathrm{sd}=.66)$ indicating a medium range of use. Meanwhile, the most intensively used strategy category was metacognitive strategies with an average score of $3.81(\mathrm{sd}=.61$ ) indicating a high level of use. The overall average was found to be 3.34 ( $\mathrm{sd}=.45$ ) indicating a medium frequency of use. Complete presentation of findings appears in Table 1.

\section{Table 1 Frequency of Use of Learning Strategy Categories}

\begin{tabular}{|c|l|c|c|c|}
\hline No. & Strategy Category & Mean & Standard Deviation & Frequency of Use \\
\hline 1. & Memory Strategies & 3.13 & .59 & Medium \\
2. & Cognitive Strategies & 3.24 & .54 & Medium \\
3. & Compensation Strategies & 3.07 & .66 & Medium \\
4. & Metacognitive Strategies & 3.81 & .61 & High \\
5. & Affective Strategies & 3.27 & .62 & Medium \\
6. & Social Strategies & 3.50 & .62 & High \\
7. & Overall Use of Strategies & 3.34 & .45 & Medium \\
\hline
\end{tabular}

The finding showing that the learners performed metacognitive and social strategies at a high range suggests that they have exercised autonomy in their learning activities. This assertion is made as the use of metacognitive strategies require the learners to independently organise and evaluate their leaming activities and the use of social strategies require them to actively and independently involve themselves in communication activities using the target language. Regarding the importance of metacognitive strategies O'Mally, Chamot, Stewner-Manzanares, Russo, and Kupper (1985:561) point out, "students without metacognitive approaches are essentially learners without direction and ability to review their progress, accomplishments, and future learning directions". Thus, generally speaking to promote better autonomy attention should be focused more on the use of the other four strategy categories including the memory, cognitive, compensation, and affective strategies.

Further analysis on the use of individual strategy revealed that several strategies in the memory, cognitive, compensation, and affective categories were also used at a high range and that some strategies in the metacognitive and social strategies category were used at a medium range. In total, out of fifty strategies under study, twenty-one strategies were used at a high frequency level. They were:

\section{Memory Strategies}

- Using new English words in sentences

- Connecting words to mental picture of situation

Cognitive Strategies

- Trying to talk like native speakers of English

- Practicing sounds of English

- Using known words in different ways

- Watching TV shows or movies in English

Compensation Strategies

- Using synonyms

Metacognitive Strategies

- Seeking many ways to use English

- Noticing mistakes and learn from them

- Paying attention when someone is speaking

- Trying to find ways to be a better leamer

- Looking for people to talk to in English

- Having clear goals for improving English skills

- Thinking about the progress in learning

\section{Affective Strategies}

- Trying to relax when afraid of using English

- Encouraging self to speak even when afraid of using English

- Noticing when tense or nervous in using English

\section{Social Strategies}

- Asking other person to slow down or repeat

- Asking to be corrected when talking

- Practicing English with other students

- Asking for help from English speakers.

This finding indicates that there are still twenty-nine strategies, the use of which needs to be intensified, as they were exercised at either moderate or low range. Thus, in order to promote higher autonomy to F2/FL learners, teaching-learning activities should be designed in such a way that the learners have a lot of opportunities to maximally 
practice using these strategies. That is, the instructional activities should be made to encourage the learners to:

1. Associate new material with the old one they already know

2. Connect word sounds with an image or a picture

3. Use rhymes to remember new words

4. Use flashcards to remember new words

5. Physically act out new words

6. Review English lessons often

7. Connect words and location such as on page, street signs, etc

8. Say or write new words several times

9. Start conversations in English

10. Read for pleasure in English

11. Write notes, messages, letters etc. in English

12. Skim then read carefully

13. Seek words in first language similar to English

14. Try to find patterns

15. Find meaning by dividing words into parts

16. Try not to translate word-by-word

17. Make summaries of new information in English

18. Guess meaning of unfamiliar words

19. Use gestures when stuck

20. Make up new words when stuck

21. Read without looking up all new words

22. Try to guess what other people will say

23. Plan schedule to have enough time to study English

24. Seek opportunities to read in English

25. Give self reward for doing well

26. Record feeling in a learning diary

27. Talk to someone else about feeling

28. Ask questions in English

29. Try to develop understanding of the culture of the native speakers of English.

In the list of strategies that require further training in use above, strategies 1-7 are memory strategies, 8-17 cognitive strategies, 18-22 compensation strategies, 23-24 metacognitive strategies, 25-27 affective strategies, and 28-29 social strategies. Technical guidelines of how to train learners to use those strategies effectively may be found in Dickinson (1987), Oxford (1990), and Harris (1997).

\section{CONCLUSION}

The link between learning strategies and learner autonomy is very close so that one can judge how autonomous F2/FL learners are from the strategies they employ in learning. This relationship is summarised by Little (1997), as he points out, If the pursuit of learner autonomy requires that we focus explicitly on the strategic capability of language learning and language use, the reverse should also be the case: focus on strategies should lead us to learner autonomy.

With regard to the Indonesian learners of English, particularly those learning English at tertiary education levels, in order to increase their autonomy in learning, the learners still need more training in the use of memory, cognitive, compensation, and affective strategies.

\section{REFERENCES}

Anderson, J. R. 1983. The Architecture of Cognitition. Cambridge, Massachusetts: Harvard University Press.

Anderson, J. R. 1990. Cognitive Psychology and Its Implications ( $3^{\text {rd }} \mathrm{Ed}$.). New York: W.H. Freeman and Company.

Broady, E. \& Kenning, M. (Eds.). 1996. Promoting Learner Autonomy in University Language Teaching. London: Centre for Information on Language Teaching and Research.

Cotterall, S. 1995. Developing a course strategy for learner autonomy. English Language Teaching Journal, 49 (3), pp.219-27.

Dickinson, L. 1987. Self-instruction in Language Learning. Cambridge: Cambridge University Press.

Dulay, H. C. \& Burt, M. K. 1974. Natural sequences in child second language acquisition. Language Learning, 24 (1), pp.37-53.

Gathercole, I. (Ed.). 1990. Autonomy in Language Learning. London: Centre for Information on Language Teaching and Research.

Gronlund, N. E. \& Linn, R. L. 1990. Measurement and Evaluation in Teaching $\left(6^{\text {th }}\right.$ Ed.). New York: Macmillan Publishing Company.

Harris, V. 1997. Teaching Learners How to Learn: strategy training in the ML classroom. London: Centre for Information on Language Teaching and Research.

Holec, H. 1980. Autonomy and Foreign Language Learning. Strasbourg: Council of Europe.

Knowles, M. 1975. Self-directed Learning: a guide for learners and teachers. Chicago: Association Press. 
Krashen, S. D. \& Terrell, T. D. 1983. The Natural Approach: language acquisition in the classroom.Oxford: Pergamon Press.

Little, D. 1990. Autonomy in language learning. In I. Gathercole (Ed.) Autonomy in Language Learning. London: Centre for Information on Language Teaching and Research.

Little D. 1997. Strategies in language learning and teaching: some introductory reflections. Paper presented at CILT Research Forum: Strategies in foreign language learning. London, 16 May 1997.

Mistar, J. (in preparation). English Learning Strategies of Indonesian Learners across Individual and Situational Differences. Ph.D thesis. Melbourne: Monash University.

Moore, B. (Ed.). 1999. The Australian Oxford Dictionary. Melboume: Oxford University Press.

Naiman, H., Frohlich, M., Stern, H. H., \& Todesco, A. 1978. The Good Language Learner. Toronto, Ontario: The Ontario Institute for Studies in Education.

O'Malley, J. M. \& Chamot, A. U. 1990. Learning Strategies in Second Language Acquisition. Cambridge: Cambridge University Press.

O’Malley, J. M., Chamot. A. U., Stewner-Manzanares, G., Russo, R. P., \& Kupper L. 1985. Leaming Strategies with Studenis of English as a Second Language, TESOL Quarterly, 19 (3), pp.557-84.

Oxford, R. L. 1990. Language Learning Strategies: what every teacher should know. New York: Newbury House Publishers.

Rubin, J. \& Thompson, 1. 1982. How to be a More Successful Language Learner. Bostob, Mass: Heinle \& Heinle.

Stern, H. H. 1983. Fundamental Concepts of Language Teaching. Oxford: Oxford University Press.

Tumber, M. 1991. Developing pupil autonomy. Language Learning Journal (4), pp. 24-6.

Wenden, A. L. 1987. Conceptual Background and Utility. In A. L. Wenden \& J. Rubin (Eds.) Learner Strategies in Language Learning. New York: Prentice Hall.

Wenden, A. 1991. Learner Strategies for Learner Autonomy. New York: Prentice Hall.

*) A paper presented at the 48th International TEFLIN Conference hosted by Indonesia University, Jakarta, 22-24 October 2000. 